\title{
Effects of Multiple Doses of Dichloroacetate on GSTZ1 Expression and Activity in Liver and Extrahepatic Tissues of Young and Adult Rats $^{\mathrm{S}}$
}

\author{
Edwin J. Squirewell, Marci G. Smeltz, Laura Rowland-Faux, Lloyd P. Horne, Peter W. Stacpoole, \\ and $\odot$ Margaret $\mathrm{O}$. James
}

\begin{abstract}
Departments of Medicinal Chemistry (E.J.S., M.G.S., L.R.-F., M.O.J.), Medicine (L.P.H., P.W.S.), and Biochemistry and Molecular Biology (P.W.S.), University of Florida, Gainesville, Florida
\end{abstract}

Received June 12, 2020; accepted August 4, 2020

\begin{abstract}
Glutathione transferase zeta 1 (GSTZ1), expressed in liver and several extrahepatic tissues, catalyzes dechlorination of dichloroacetate (DCA) to glyoxylate. DCA inactivates GSTZ1, leading to autoinhibition of its metabolism. DCA is an investigational drug for treating several congenital and acquired disorders of mitochondrial energy metabolism, including cancer. The main adverse effect of DCA, reversible peripheral neuropathy, is more common in adults treated long-term than in children, who metabolize DCA more quickly after multiple doses. One dose of DCA to Sprague Dawley rats reduced GSTZ1 expression and activity more in liver than in extrahepatic tissues; however, the effects of multiple doses of DCA that mimic its therapeutic use have not been studied. Here, we examined the expression and activity of GSTZ1 in cytosol and mitochondria of liver, kidney, heart, and brain 24 hours after completion of 8-day oral dosing of $100 \mathrm{mg} / \mathrm{kg}$ per day sodium DCA to juvenile and adult Sprague Dawley rats. Activity was measured with DCA and with 1,2-epoxy-3-(4-nitrophenoxy)propane (EPNPP), reported to be a GSTZ1-selective substrate. In DCA-treated rats, liver retained higher expression and activity of GSTZ1 with DCA than
\end{abstract}

other tissues, irrespective of rodent age. DCA-treated juvenile rats retained more GSTZ1 activity with DCA than adults. Consistent with this finding, there was less measurable DCA in tissues of juvenile than adult rats. DCA-treated rats retained activity with EPNPP, despite losing over $98 \%$ of GSTZ1 protein. These data provide insight into the differences between children and adults in DCA elimination under a therapeutic regimen and confirm that the liver contributes more to DCA metabolism than other tissues.

\section{SIGNIFICANCE STATEMENT}

Dichloroacetate (DCA) is one of few drugs exhibiting higher clearance from children than adults, after repeated doses, for reasons that are unclear. We hypothesized that juveniles retain more glutathione transferase zeta 1 (GSTZ1) than adults in tissues after multiple DCA doses and found this was the case for liver and kidney, with rat as a model to assess GSTZ1 protein expression and activity with DCA. Although 1,2-epoxy-3-(4-nitrophenoxy)propane was reported to be a selective GSTZ1 substrate, its activity was not reduced in concert with GSTZ1 protein.

\section{Introduction}

Glutathione transferase zeta 1 (GSTZ1)/maleylacetoacetate isomerase is a cytosolic and mitochondrial enzyme with a critical role in tyrosine catabolism, catalyzing the trans-isomerization of maleylacetoacetate (MAA) and maleylacetone (MA) into fumarylacetoacetate and fumarylacetone, respectively (Blackburn et al., 1998; Li et al., 2011). Although the conversion of MAA and MA is an important physiologic function of the enzyme, GSTZ1 also catalyzes the glutathionedependent dehalogenation of dichloroacetate (DCA) to glyoxylate (Tong et al., 1998). The GSTZ1-catalyzed conversion of DCA to glyoxylate represents the primary metabolic route for DCA. GSTZ1 is the only enzyme known to metabolize DCA to glyoxylate. However, secondary metabolites derived from the formation of glyoxylate have

This work was supported in part by the US Public Health Service [Grant RO1 GM 099871]

https://doi.org/10.1124/dmd.120.000142.

S This article has supplemental material available at dmd.aspetjournals.org. also been identified, including carbon dioxide, glycine, and oxalate (Gonzalez-Leon et al., 1997; James et al., 1998, 2017).

DCA is a byproduct from municipal drinking water chlorination, present at concentrations as high as $160 \mu \mathrm{g} / \mathrm{l}$ in some municipalities (Miller and Uden, 1983; Jia et al., 2006; Stacpoole, 2011). High doses of DCA administered to inbred strains of rodents demonstrate hepatocellular carcinogenicity in experimental animals (Deangelo et al., 1991; DeAngelo et al., 1996), but carcinogenic effects in humans have not been observed (IARC Working Group on the Evaluation of Carcinogenic Risks to Humans, 2014). Notably, DCA is an investigational drug for the treatment of cancer and other diseases of mitochondrial dysfunction via its inhibition of pyruvate dehydrogenase kinase and stimulation of the mitochondrial pyruvate dehydrogenase complex (Kankotia and Stacpoole, 2014; James and Stacpoole, 2016; James et al., 2017). In addition, DCA is currently used in a phase 3 clinical trial for treatment in children with congenital pyruvate dehydrogenase complex deficiency (NCT02616484, ClinicalTrials.gov) (Stacpoole et al., 2018). This underscores the important therapeutic applications of DCA in humans.

ABBREVIATIONS: DCA, dichloroacetate; EPNPP, 1,2-epoxy-3-(4-nitrophenoxy)propane; GC-MS, gas chromatography-mass spectrometry; GSH, glutathione; GSTZ1, glutathione transferase zeta 1; MA, maleylacetone; MAA, maleylacetoacetate. 
The pharmacology and toxicity of DCA are influenced, in part, by subject age (Shroads et al., 2008). For example, the chronic use of DCA in adults can lead to development of reversible peripheral neuropathy (Kaufmann et al., 2006; Stacpoole et al., 2019). However, this effect is seldom clinically symptomatically observed in children (Stacpoole, 2011; Abdelmalak et al., 2013), who metabolize DCA more quickly after multiple doses than adults (Shroads et al., 2008; Mangal et al., 2018). In people, DCA metabolism is independent of sex (Stacpoole et al., 1998). DCA is a mechanism-based inactivator of GSTZ1 (Anderson et al., 1999; Tzeng et al., 2000), and repetitive DCA dosing results in the autoinhibition of DCA metabolism (Li et al., 2008). Tissue accumulation of DCA, MAA, and MA, due to GSTZ1 degradation, may be a mechanism responsible for DCA toxicity, as MA and MAA are capable of forming covalent modifications to proteins (Cornett et al., 1999; Lantum et al., 2002b).

Although liver is the main site of GSTZ1 expression and activity, extrahepatic tissues also express GSTZ1 (Board et al., 1997; Lantum et al., 2002a; Jahn et al., 2018). Therefore, elimination and disposition of DCA can be influenced by extrahepatic metabolism. It was shown that a single dose of a therapeutic concentration of DCA to female rats reduced GSTZ1 expression and activity in liver to a greater extent than in kidney, brain, and heart (Jahn et al., 2018), such that DCA metabolism was more prominent in these extrahepatic tissues than liver after the single dose. DCA is given on a daily basis under therapeutic conditions; however, the role of extrahepatic tissues in metabolism of DCA, MAA, and MA after repeated doses of DCA that mimic therapy has not been studied. We hypothesized that extrahepatic tissues contribute to the GSTZ1-catalyzed metabolism of DCA after multiple doses of the drug. Moreover, given the influence of subject age on DCA pharmacology, we also hypothesized that children retain a greater capacity for the GSTZ1catalyzed metabolism of DCA. This study examines the effect of repetitive DCA dosing on the expression and activity of GSTZ1 in tissues of juvenile and adult Sprague Dawley rats, which have been used previously to model the effects of DCA exposure in relation to neuropathy, a side effect of DCA therapy (Calcutt et al., 2009).

Measuring GSTZ1 activity with its established substrates, DCA or MA, is expensive and time consuming; therefore, we were interested to read reports that 1,2-epoxy-3-(4-nitrophenoxy)propane (EPNPP) was a GSTZ1-selective substrate in two species of monkeys (Uno et al., 2013, 2020). Measuring activity with EPNPP is inexpensive and rapid (Habig et al., 1974), so we used this substrate as well as DCA to monitor activity in control and DCA-treated rats, as well as with recombinant rat and human GSTZ1.

\section{Materials and Methods}

Chemicals, Animals, and Reagents. Four-week-old and 52-week-old male and female Sprague Dawley rats were purchased from Charles River Laboratories (Wilmington, MA) and approved for use by the University of Florida Institutional Animal Care and Use Committee. A custom polyclonal rabbit antibody to the fulllength rat GSTZ1 protein (National Center for Biotechnology Information accession number: NM_001109445.1) was produced by Cocalico Custom Antibody (Reamstown, PA) and isolated from serum at $4{ }^{\circ} \mathrm{C}$ using the Protein A IgG Purification Kit (Thermo Scientific, Waltham, MA). TransBlot Turbo nitrocellulose RTA Transfer Kit, TGX Stain-free FastCast 12\% Acrylamide kit, Clarity Western ECL Substrate reagent, 10X Tris/Glycine/SDS Buffer, Blottinggrade blocker nonfat dry milk, and Precision Plus Protein Dual Color Standards were purchased from Bio-Rad Laboratories (Hercules, CA). We obtained HEPES, sodium chloride, sucrose, dithiothreitol, glutathione (GSH), glycerol, potassium chloride, boron trifluoride-methanol solution, 2-keto-hexanoic acid [gas chromatography-mass spectrometry (GC-MS) internal standard], and anti-rabbit horseradish peroxidase secondary antibody from Sigma Aldrich (St Louis, MO). The Pierce BCA Protein Assay Kit was purchased from ThermoFisher Scientific. EPNPP was purchased from AK Scientific (Union City, CA). We purchased clinical grade sodium DCA from TCI America (Portland, OR) and analyzed it by GC-MS to verify that it was $>99 \%$ pure and did not contain mono- or trichloroacetate. Sodium acetate was purchased from Tocris Bioscience (Minneapolis, MN) and $\left[{ }^{14} \mathrm{C}\right]-\mathrm{DCA}$ from American Radiolabeled Chemicals (St. Louis, MO). Radioactive samples were analyzed with a Beckman model LS-6500 liquid scintillation counter using EcoLume liquid scintillation cocktail (MP Biomedicals, Solon, OH). Immunoblots were visualized using the ChemiDoc Imaging System from Bio-rad Laboratories. All other reagents were purchased from commercial suppliers.

Rat Dosing and Tissue Collection. Adult female $(n=16)$, adult male $(n=4)$, juvenile female $(n=8)$, and juvenile male rats $(n=10)$ were dosed with sodium DCA $(100 \mathrm{mg} / \mathrm{kg})$ or sodium acetate $(100 \mathrm{mg} / \mathrm{kg})$ by oral gavage daily for eight consecutive days in groups of four to eight per treatment. The means \pm S.D. of initial body weights (grams) for adult female, adult male, juvenile female, and juvenile male rats were $413 \pm 54,768 \pm 89,83 \pm 6$, and $89 \pm 9$, respectively. Because of the rapid growth in juvenile rats, dosing was adjusted to the body weight determined each day of the treatment period. The weight of the adult rats did not change over the dosing period. On the ninth day the animals were sacrificed, and the liver, kidney, heart, and brain organs were collected and used to prepare cytosolic and mitochondrial subcellular fractionations as previously described (Li et al., 2011). We selected the rat DCA dose of $100 \mathrm{mg} / \mathrm{kg}$ because it was calculated to be therapeutically similar to the human dose of $25 \mathrm{mg} / \mathrm{kg}$ per day after species scaling (Boxenbaum, 1980), and sodium acetate was chosen as control since it is a similar molecule to DCA that was previously shown to have no effect on GSTZ1 expression or activity (Jahn et al., 2018; Smeltz et al., 2019). Four- and 52-week-old rats were used to model children or adults around the ages of 2 and 30 years, respectively (Quinn, 2005), and a treatment period of 8 days was chosen as studies in humans and rats show that a steady state reduction in GSTZ1 is achieved between 5 and 7 days (Schultz and Sylvester, 2001; Saghir and Schultz, 2005; Shroads et al., 2012).

Recombinant Rat and Human GSTZ1. Expressed human and rat GSTZ1 were prepared and purified as described in previous work (Li et al., 2012; Smeltz et al., 2019).

GSTZ1 Protein Expression. GSTZ1 protein expression was assessed by Western blot using a ratio standard curve constructed from purified recombinant rat GSTZ1 and a cytosolic protein reference sample (Supplemental Fig. 1). Known amounts of cytosolic and mitochondrial protein were denatured for 5 minutes at $100^{\circ} \mathrm{C}$ in $1 \mathrm{X}$ sample buffer (Alfa Aesar, Havervill, MA) containing $20 \mathrm{mM}$ HEPES, $40 \mathrm{mM} \mathrm{NaCl}, 2 \mathrm{mM} \mathrm{GSH}$, and $2 \mathrm{mM}$ dithiothreitol. The proteins were separated by SDS-PAGE, applying more protein per lane for samples derived from DCA-treated animals to ensure the GSTZ1 levels were within the linear range of the standard curve. Subsequently, the proteins were transferred to nitrocellulose membranes using the Trans-blot Turbo Transfer System (Bio-rad Laboratories) and then blocked for 1 hour at room temperature in 5\% milk prepared in TBST (Tris-buffered saline containing $0.05 \%$ Tween 20). The membranes were probed overnight at $4{ }^{\circ} \mathrm{C}$ using a rat GSTZ1 antibody dilution of $1: 10,000$ in $5 \%$ milk. On the following morning and at room temperature, the membranes were washed in TBST for 30 minutes (buffer changed every 5 minutes), incubated for 1 hour in secondary anti-rabbit horseradish peroxidase antibody (1:5000, prepared in 5\% milk), and washed again in TBST as described above. The membranes were incubated in Clarity ECL substrate prepared from one part luminol/enhancer solution, one part peroxide solution, and five parts water. GSTZ1 bands were visualized using the ChemiDoc system (Bio-rad Laboratories), where the chemiluminescent signal for each sample was normalized against the cytosolic protein reference sample from the standard curve. We show representative immunoblots of cytosolic GSTZ1 protein in liver, kidney, heart, and brain of acetate- and DCA-treated young female rats in Supplemental Figures 2-5. The expression of GSTZ1 (nanograms GSTZ1 per microgram protein) is reported as the mean \pm S.D. of duplicate determinations.

GSTZ1 Activity Assays. Subcellular fractions from liver and extrahepatic tissues were examined for GSTZ1 activity by measuring the conversion of $\left[{ }^{14} \mathrm{C}\right]-$ DCA to $\left[{ }^{14} \mathrm{C}\right]$-glyoxylate as previously described (Li et al., 2011; Smeltz et al., 2019). Each $100 \mu l$ reaction was performed at $\mathrm{pH} 7.6$ and contained $100 \mathrm{mM}$ HEPES, $0.2 \mathrm{mM}\left[{ }^{14} \mathrm{C}\right]-\mathrm{DCA}$, and either $1 \mathrm{mM}$ GSH (cytosol), $5 \mathrm{mM} \mathrm{GSH}$ (liver mitochondria), or $10 \mathrm{mM} \mathrm{GSH}$ (kidney mitochondria). Since GSH is consumed by gamma-glutamyl transpeptidase activity in rat kidney mitochondria (Jahn et al., 2018), we used $10 \mathrm{mM} \mathrm{GSH}$ in the current work to maintain GSH saturation for all kidney mitochondria incubations. The reactions were initiated at $37^{\circ} \mathrm{C}$ by the 
addition of dialyzed protein $(0.1-1.0 \mathrm{mg})$ for 10-30 minutes for liver samples and up to 120 minutes for extrahepatic tissue samples. Incubations were then quenched with methanol and examined for $\left[{ }^{14} \mathrm{C}\right]$-glyoxylate by the HPLC method (Li et al., 2011). To determine the contribution of each organ to DCA metabolism, we calculated the total activity per organ (nanomoles glyoxylate formed per minute per whole tissue) from the specific activity in cytosol and mitochondria (nanomoles glyoxylate formed per minute per milligram protein), the protein yield of each subcellular fraction (milligrams protein per gram tissue), and the total weight of the organ (grams). The total activity per organ was then normalized to the rodent's weight (nanomoles glyoxylate formed per minute per kilogram rat) and is expressed as the mean \pm S.D. of duplicate determinations. For liver and kidney cytosol, we also calculated activity per gram tissue and per whole tissue.

Activity Assay with EPNPP. Liver cytosol fractions from acetate- and DCAtreated young female rats were examined for activity using EPNPP as substrate. EPNPP was also examined as substrate with purified recombinant rat and human GSTZ1. Briefly, each reaction was performed at $37^{\circ} \mathrm{C}$ and contained $10 \mathrm{mM}$ potassium phosphate $\mathrm{pH} 7.4,1 \mathrm{mM} \mathrm{GSH}$, and $1 \mathrm{mM}$ EPNPP in a final reaction volume of $3.0 \mathrm{ml}$. The reactions were initiated by the addition of rat liver cytosol $(0.5 \mathrm{mg})$ or purified rat or human GSTZ1 $(0.3 \mathrm{mg})$ for 5 minutes, where formation of the glutathione conjugate of EPNPP at $360 \mathrm{~nm}$ was recorded. Calculation of specific activity (nanomoles per minute per milligram protein) was based on $0.5 \mathrm{mM}^{-1} \mathrm{~cm}^{-} 1$ as the molar extinction coefficient of the GSH conjugate of EPNPP (Habig et al., 1974).

Comparison of GSTZ1 Protein Sequences between Species. The amino acid sequences of human, rat, and marmoset GSTZ1 were compared for similarity using Basic Local Alignment Search Tool (National Center for Biotechnology Information). The protein sequences were obtained from the following UniPortKB accession identifiers: O43708 (MAAI_HUMAN), P57113 (MAAI_RAT), F7A4H9 (F7A4H9_CALJA), and U3AQX4 (U3AQX4_CALJA).

Quantitation of DCA. To determine DCA concentrations, sections of whole tissue (0.1-0.3 g) from liver, kidney, heart, and brain of control- and DCA-treated rats were homogenized in $12 \%$ boron-trifluoride methanol solution $(1 \mathrm{ml})$ to derivatize DCA to the methyl ester by heating the samples at $115^{\circ} \mathrm{C}$ for 15 minutes, then cooling to $4^{\circ} \mathrm{C}$. Methyl-DCA was extracted into methylene chloride for subsequent analysis by GC-MS (Yan et al., 1997). GC-MS analysis was performed using an Agilent GC 7890B (column: Thermo TG WAXMS, $30 \mathrm{~m}$ $\times 0.25 \mathrm{~mm} \times 0.25 \mu \mathrm{m}$ ), Agilent 5977B mass spectrometer with Agilent 7693 autosampler. Quantitation was performed using $\mathrm{m} / \mathrm{z} 59$ for a fragment of methyl DCA versus $\mathrm{m} / \mathrm{z} 57$ for the most abundant fragment of methylated internal standard, 2-ketohexanoic acid, and MSD ChemStation software (Agilent).

Data Analysis. Data transformation and determination of means, S.D., and statistical significance were performed using GraphPad Prism 6 software (San Diego, CA). Group comparisons within subcellular fractions used either the oneway ANOVA (corrected for multiple comparisons by the Tukey method) or a twotailed Student's $t$ test (corrected for multiplicity by the Holm-Sidak method). Statistical significance was defined as $P<0.05$.

\section{Results}

Cytosolic and Mitochondrial GSTZ1 Protein Expression Is Reduced After Eight Daily DCA Doses in Rats. Data were obtained using 16 adult females (eight per group), four adult control (acetatetreated) males, 10 young males (four DCA-treated, six acetate-treated), and eight young female rats (four per group). Additional control, acetatetreated young males were used because of high variability of control values in the four used initially. As seen in Figure 1, repetitive DCA dosing significantly reduced the expression of cytosolic GSTZ1 in liver and extrahepatic tissues of young and adult rats. Of the tissues studied, liver retained the highest expression in adults, at $0.030 \pm 0.026 \mathrm{ng}$

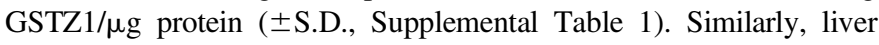
retained the highest expression of cytosolic GSTZ1 in DCA-treated juveniles (Supplemental Table 2). In controls, the expression of cytosolic GSTZ1 was similar in young and adult females $(1.0 \pm 0.4$ and $1.1 \pm 0.1 \mathrm{ng} \mathrm{GSTZ1/ \mu g}$ protein, respectively). In male control rats dosed with $100 \mathrm{mg} / \mathrm{kg}$ sodium acetate, GSTZ1 protein expression
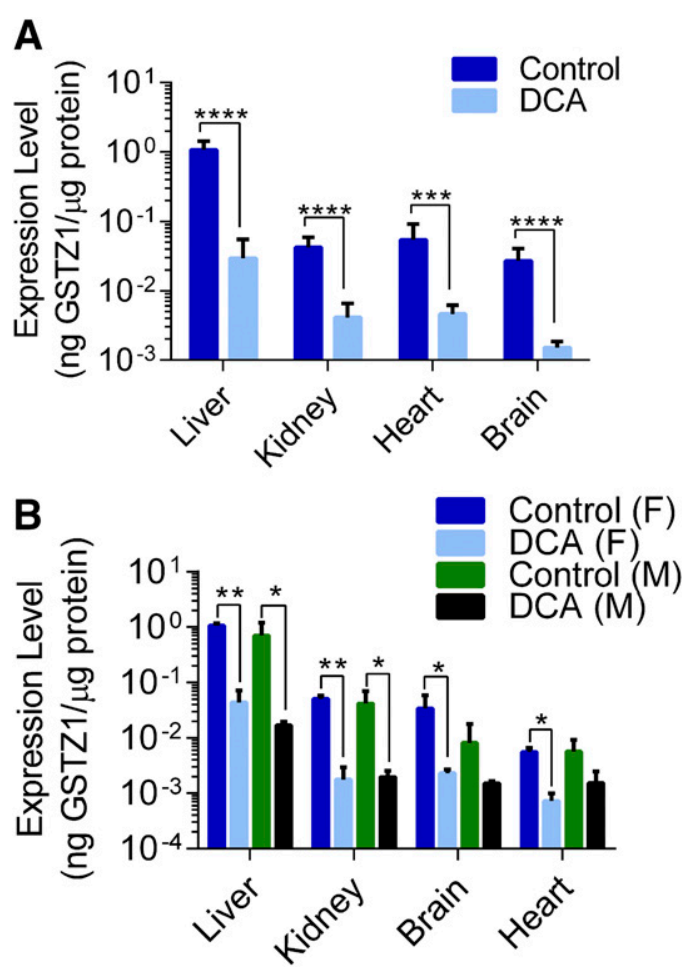

Fig. 1. Cytosolic GSTZ1 protein expression in liver, kidney, heart, and brain of adult female (A) and juvenile male and female (B) rats administered eight daily oral doses of $100 \mathrm{mg} / \mathrm{kg}$ sodium acetate (control) or $100 \mathrm{mg} / \mathrm{kg}$ sodium DCA. Male and female sexes are denoted by $(\mathrm{M})$ and $(\mathrm{F})$, respectively. Data are means \pm S.D.s; $n=8$ per group (adults), four per group (juvenile females), six for control, and four for DCA-treated juvenile males. $* * * * P<0.0001$; ***P $P<0.001 ; * * P<0.01$; $* P<0.05$.

showed high individual variability both in juveniles and adults. After 8-day dosing with $100 \mathrm{mg} / \mathrm{kg}$ sodium acetate, adult male rats demonstrated $1.05 \pm 0.52 \mathrm{ng}$ cytosolic GSTZ1/ $\mu \mathrm{g}$ protein in liver, and juvenile males had $0.70 \pm 0.49 \mathrm{ng}$ GSTZ1/ $\mu \mathrm{g}$ protein. These control levels were not significantly different from those in females (Supplemental Tables 1 and 2).

As with cytosolic GSTZ1, mitochondrial GSTZ1 was significantly reduced in rat tissues after 8-day dosing with DCA (Fig. 2). Adult rat kidney retained the highest expression at $0.048 \pm 0.019 \mathrm{ng} \mathrm{GSTZ1} / \mu \mathrm{g}$ protein (Supplemental Table 3). The hepatic expression of mitochondrial GSTZ1 in DCA-treated adults was $0.020 \pm 0.008$, whereas levels in heart and brain were much lower $(0.0013 \pm 0.0017$ and $0.0012 \pm$ 0.0010 , respectively). These findings were a likely indication that juveniles would also express very low levels of mitochondrial GSTZ1 after multiple DCA dosages. Our investigation of mitochondrial GSTZ1 expression in young rats was limited to liver and kidney tissue, in part because the small size of brain and heart from the young rats made it difficult to isolate sufficient mitochondria to study. These results, summarized in Supplemental Table 4, show mitochondrial GSTZ1 was more highly retained in liver after DCA dosing in juveniles. There were no gender-dependent variations in mitochondrial GSTZ1 expression for either age group.

Repetitive DCA Dosing in Rats Decreases Cytosolic and Mitochondrial GSTZ1 Activity with DCA in Extrahepatic Tissues to a Greater Extent Than Liver. We measured the activity of GSTZ1 in mitochondrial and cytosolic matrices from rat liver and some extrahepatic tissues. In general, there was strong correlation between GSTZ1 protein expression and GSTZ1 activity. The average activity in liver cytosol of adult male and female controls was $2.20 \pm 0.47$ and 2.89 
A
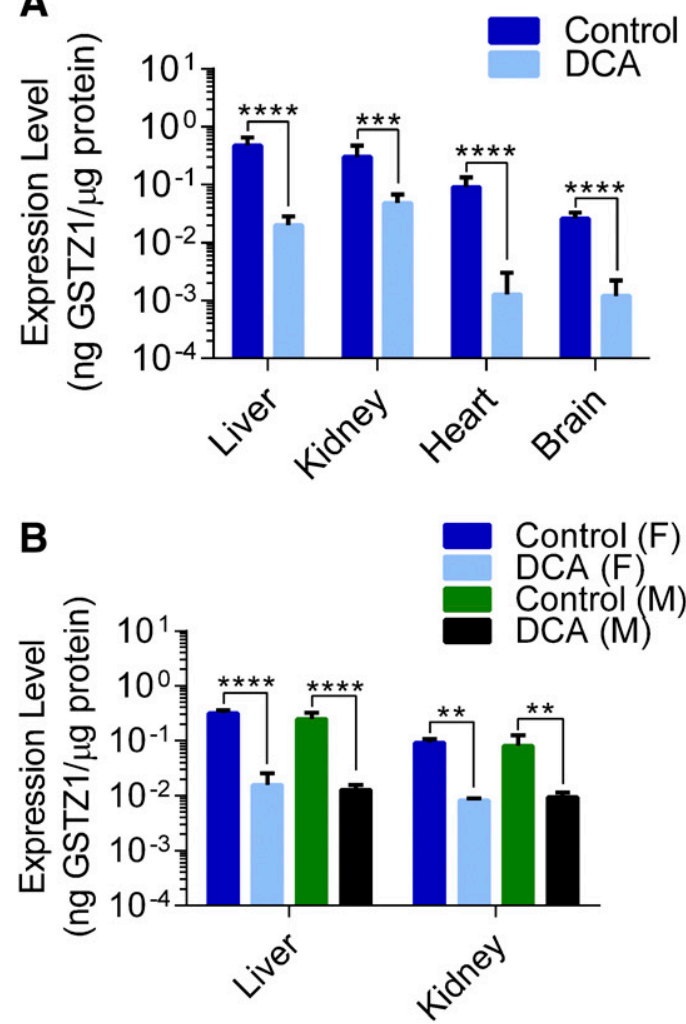

Fig. 2. Expression of mitochondrial GSTZ1 in liver, kidney, heart, and brain of adult female (A) and juvenile male and female (B) rats given eight daily doses of $100 \mathrm{mg} / \mathrm{kg}$ sodium acetate (control) or $100 \mathrm{mg} / \mathrm{kg}$ sodium DCA. Male and female sexes are denoted by $(\mathrm{M})$ and $(\mathrm{F})$, respectively. Data are means \pm S.D.s; $n=8$ per group (adults) and four or six per group (juveniles). **** $P<0.0001$; *** $P<$ $0.001 ; * * P<0.01 ; * P<0.05$.

$\pm 0.54 \mathrm{nmol}$ glyoxylate/min per milligram protein ( \pm S.D.), respectively. After DCA dosing in adult females, GSTZ1 activity in hepatic cytosol was reduced over $90 \%$ to $0.026 \pm 0.008 \mathrm{nmol} / \mathrm{min}$ per milligram. Nevertheless, liver retained the highest activity of cytosolic GSTZ1 in DCA-treated adult rats, as activity in extrahepatic tissues was $0.002 \mathrm{nmol} / \mathrm{min}$ per milligram or lower (Supplemental Table 5). The trend was similar in juvenile rats. In liver cytosol, young male and female controls demonstrated GSTZ1 activities of $1.83 \pm 0.81$ and 1.95 $\pm 0.48 \mathrm{nmol} / \mathrm{min}$ per milligram, respectively, whereas the activity decreased to $0.034 \pm 0.007$ and $0.040 \pm 0.011 \mathrm{nmol} / \mathrm{min}$ per milligram in males and females dosed with DCA (Supplemental Table 6). There was low activity in kidney cytosol of DCA-treated juveniles $(0.004 \pm$ 0.001 for males, $0.005 \pm 0.003$ for females); rates in heart and brain cytosol were not determined as they were expected to be at the limit of detection with the low amount of tissue we had. Additionally, interrogation of mitochondrial GSTZ1 activity was limited to liver and kidney fractions. Liver retained the highest activity of mitochondrial GSTZ1 in DCA-treated adults with an average rate of $0.005 \pm 0.008$ (vs. kidney rate of $0.0007 \pm 0.0003 \mathrm{nmol} / \mathrm{min}$ per milligram, Supplemental Table 7). The remaining rates for juvenile controls are summarized in Supplemental Table 8. The total cytosolic and mitochondrial activity in tissues studied are summarized on a whole rat basis in Tables 1 and 2, respectively, for adult and juvenile rats. For further comparisons, we calculated the cytosolic activities remaining in DCA-treated adult and juvenile liver and kidney on a per gram tissue and per whole organ basis, as shown in Figure 3.

Proportion of Liver to Body Weight Is Higher in Juvenile Rats Than Adults. The percent weight of the liver (grams) relative to total body weight (grams) was calculated for each rodent. Adult males and females demonstrated liver to body weight percentages of $3.49 \pm 0.21$ and $3.56 \pm 0.48$ ( \pm S.D.), respectively, whereas the values in juvenile male and female rats were significantly higher $(P<0.0001)$ at $6.08 \pm$ 0.63 and $5.94 \pm 0.80$. The body and liver weights from each rat group are summarized in Supplemental Table 9.

Activity with EPNPP Did Not Change with DCA Treatment. We examined liver cytosol from acetate- and DCA-treated rats to determine if the loss of GSTZ1 protein by repetitive DCA dosages would show an effect on activity with EPNPP. Additionally, we examined whether the conjugation of EPNPP was catalyzed by the human or rat GSTZ1 protein. Our studies showed the activity with EPNPP in DCA-treated young females $(131.6 \pm 39.7 \mathrm{nmol} / \mathrm{min}$ per milligram, \pm S.D.) was not significantly different from activity in controls $(132.8 \pm 38.1 \mathrm{nmol} / \mathrm{min}$ per milligram, $P=0.97)$. Furthermore, incubations of EPNPP with purified recombinant rat or human GSTZ1 did not show an increase in absorbance at $360 \mathrm{~nm}$ after 5 minutes (data not shown), nor could a reliable rate be obtained when the incubation time was extended to 10 minutes (data not shown). To confirm catalytic activity of the recombinant enzymes, we incubated purified rat GSTZ1 and human GSTZ1C with $\left[{ }^{14} \mathrm{C}\right]$-DCA using the assay conditions described for GSTZ1 activity in Materials and Methods. We found the activities for rat GSTZ1 and human GSTZ1C were 598 and 65 nmol glyoxylate formed/min per milligram, respectively.

After 8-Day DCA Dosing, DCA Concentrations in Adult Rat Tissues Are Higher Than in Juvenile Rats. DCA was detected in whole tissues of young and adult rats 24 hours after eight daily doses of $100 \mathrm{mg} / \mathrm{kg}$ DCA. As seen in Table 3, DCA concentrations in all adult tissues were significantly higher than in juveniles. No differences in tissue concentrations between male and female juveniles were observed.

\section{Discussion}

GSTZ1 has a critical physiologic role in tyrosine catabolism, although the expression and activity of GSTZ1 are also important for the disposition and elimination of DCA, as GSTZ1 is the only enzyme known to metabolize DCA. Much attention has been given to DCA in recent years because of its therapeutic application in cancer and other metabolic diseases, in which there is dysfunction of the pyruvate dehydrogenase complex/pyruvate dehydrogenase kinase axis and subsequent perturbation of mitochondrial bioenergetics (James et al., 2017). However, the chronic effects of DCA administration vary among individuals. Diversity in GSTZ1 haplotype is known to affect the pharmacokinetics of DCA (Board and Anders, 2011; Li et al., 2012; Zhong et al., 2014; Tian et al., 2019). Other variables contributing to differential responses to DCA are age (Kaufmann et al., 2006; Stacpoole, 2011; Shroads et al., 2012; Abdelmalak et al., 2013) and tissue chloride concentrations, as chloride slows the inactivation of GSTZ1 by DCA (Zhong et al., 2014; Jahn et al., 2018; Smeltz et al., 2019).

The distribution and activity of GSTZ1 in rodent tissues has been studied previously (Lantum et al., 2002a). Recently, we reported that a single "therapeutic" dose of DCA to rats reduced the activity and expression of GSTZ1, but the effect in extrahepatic tissues was weaker than in liver (Jahn et al., 2018). Given this observation, we hypothesized that extrahepatic tissues contribute more to DCA metabolism than liver after multiple doses of DCA. We tested this hypothesis in the current work by dosing Sprague Dawley rats with $100 \mathrm{mg} / \mathrm{kg}$ DCA for 8 days. Additionally, we hypothesized that juveniles retain a higher capacity for the GSTZ1-catalyzed metabolism of DCA. This premise was formulated based on age-related effects of chronic DCA use in humans and the 
TABLE 1

Total GSTZ1 activity per whole tissue in adult female rats given eight daily oral doses of $100 \mathrm{mg} / \mathrm{kg}$ sodium acetate (control) or $100 \mathrm{mg} / \mathrm{kg}$ sodium DCA, normalized to body weight

Values are means \pm S.D. of duplicate determinations; $\mathrm{n}=8$ (cytosol, controls), 4-8 (cytosol, DCA-treated), 8 (mitochondria, controls), or 2-8 (mitochondria, DCA-treated).

\begin{tabular}{|c|c|c|c|c|}
\hline \multirow{2}{*}{ Tissue } & \multicolumn{2}{|c|}{ Adult cytosolic GSTZ1 } & \multicolumn{2}{|c|}{ Adult mitochondrial GSTZ1 } \\
\hline & Control & DCA & Control & DCA \\
\hline & nmol glyoxylate/min per kilogram rat & nmol glyoxylate/min per kilogram rat & nmol glyoxylate/min per kilogram rat & nmol glyoxylate/min per kilogram rat \\
\hline Liver $^{a}$ & $4036 \pm 1006$ & $44.7 \pm 13.4 * * * *$ & $376 \pm 105$ & $6.5 \pm 9.6^{* * * *}$ \\
\hline Kidney & $71.5 \pm 22.1$ & $0.48 \pm 0.12 * * * *$ & $3.8 \pm 0.9$ & $0.06 \pm 0.03 * * *$ \\
\hline Brain & $4.0 \pm 1.0$ & $0.031 \pm 0.008 * * * *$ & ND & ND \\
\hline Heart & $1.4 \pm 0.6$ & $0.020 \pm 0.004 * * *$ & ND & ND \\
\hline
\end{tabular}

ND, not determined.

${ }^{a}$ Total activity in cytosol was calculated based on the cytosolic yield recovered experimentally. We used a mitochondrial yield of $30 \mathrm{mg} / \mathrm{g}$ liver to correct for the loss of mitochondria during isolation (Fleischer et al., 1979). The asterisks denote statistical significance when compared with activity within the same tissue of controls: $* * * * P<0.0001 ; * * * P<0.001$.

larger liver to body weight ratio in children (Noda et al., 1997; Shroads et al., 2008).

GSTZ1 was detected in cytosolic and mitochondrial subcellular fractions from acetate- and DCA-treated rats, although the expression and activity were significantly lower in fractions from the DCA group. There was a strong correlation between expression and activity of GSTZ1 for each sample, which has been described previously (Jahn et al., 2018; Smeltz et al., 2019). Of the tissues examined, liver retained the highest expression and activity of GSTZ1 irrespective of rodent age or gender. Indeed, the total activity per organ from cytosolic and mitochondrial GSTZ1 (Tables 1 and 2, respectively) show that extrahepatic tissues have no greater contribution to DCA metabolism than liver after multiple drug doses. Furthermore, considering the higher protein yield and larger size of the liver compared with those of extrahepatic tissues, our findings demonstrate that most DCA metabolism occurs in the liver, even after repeated drug exposure. These data are consistent with human studies, which show no sex difference in DCA kinetics (Stacpoole et al., 1998), as well as with a clinical study demonstrating that during the anhepatic phase of liver transplantation, DCA plasma clearance was undetectable (Shangraw and Fisher, 1996).

Of note, there was a greater reduction of total cytosolic GSTZ1 activity in liver and kidney of DCA-treated adults than in juveniles. The total activity in liver cytosol was $113 \pm 37$ and $115 \pm 33 \mathrm{nmol}$ glyoxylate/min per kilogram rat, respectively, for juvenile male and females, whereas the remaining activity in liver cytosol of 52-week-old female rats was $44.7 \pm 13.4$ nmol glyoxylate/min per kilogram rat (Tables 1 and 2). Here, the total activity retained in liver cytosol of adults was 2.6-fold lower than the levels in juveniles $(P<0.001)$. Comparison of the activity in kidney cytosol revealed there were also lower levels of cytosolic GSTZ1 in adults $(P<0.001)$. To ensure that our calculation of remaining activity on a per kilogram rat basis did not skew the results, we also calculated the activity remaining in liver and kidney cytosol after DCA dosing per gram tissue and per whole organ: these results are shown in Figure 3. Although the remaining activity varied slightly with calculation method, the conclusion that juveniles retain more activity after repeat DCA doses did not change. The cytoplasm is the major subcellular location of GSTZ1, and these findings suggest that juveniles have a greater capacity for DCA metabolism in cytosolic matrices after multiple doses of DCA. Given the greater proportion of liver to body weight in juveniles, the hepatic metabolism of DCA is predicted to be augmented within this age group. This is consistent with the higher clearance of DCA observed in young populations (Shroads et al., 2008; Mangal et al., 2018), as children may retain a higher capacity for the GSTZ1-catalyzed metabolism of DCA due to relative liver size.

There is recent evidence that macaque and marmoset GSTZ1 catalyze the conjugation of glutathione to EPNPP (Uno et al., 2013, 2020). Prior to these reports, the biotransformation of haloacetic acids and trans-isomerization of MAA and MA were the only reactions described in literature to be catalyzed by GSTZ1 (Tong et al., 1998; Board et al., 2001). Our results, showing no decrease in activity with EPNPP in liver cytosol of DCA-treated rats, reveal that EPNPP is not a substrate for the rat GSTZ1. Furthermore, no activity with EPNPP was found with expressed human or rat GSTZ1 proteins. One explanation for the difference in EPNPP activity between species could relate to differences in protein sequence. Human GSTZ1 and marmoset GSTZ1 share 90\% amino acid sequence according to recent reports (Uno et al., 2020). Our analysis indicated the percent identity between human and marmoset GSTZ1 was slightly lower $(88 \%)$ and that the sequences differed by the presence of a motif $\left({ }^{124} V_{S K D L R E}{ }^{130}\right)$ in marmoset GSTZ1

TABLE 2

Total GSTZ1 activity per whole tissue in juvenile rats given eight daily oral doses of $100 \mathrm{mg} / \mathrm{kg}$ sodium acetate (control) or $100 \mathrm{mg} / \mathrm{kg}$ sodium DCA, normalized to body weight

Values are means \pm S.D. of duplicate determinations; $\mathrm{nn}=4$ per group.

\begin{tabular}{|c|c|c|c|c|}
\hline \multirow{2}{*}{ Tissue } & \multicolumn{2}{|c|}{ Juvenile females (cytosolic GSTZ1) } & \multicolumn{2}{|c|}{ Juvenile males (cytosolic GSTZ1) } \\
\hline & Control & DCA & Control & DCA \\
\hline & nmol glyoxylate/min per kilogram rat & nmol glyoxylate/min per kilogram rat & nmol glyoxylate/min per kilogram rat & nmol glyoxylate/min per kilogram rat \\
\hline Liver $^{a}$ & $3947 \pm 1462$ & $115 \pm 33 * * *$ & $4103 \pm 2684$ & $113 \pm 37 * * *$ \\
\hline Kidney & $67.6 \pm 19.3$ & $1.4 \pm 1.0^{* * *}$ & $81.0 \pm 29.6$ & $1.8 \pm 0.3^{* * *}$ \\
\hline Brain & $2.6 \pm 0.4$ & ND & $1.4 \pm 1.4$ & ND \\
\hline Heart & $1.9 \pm 0.7$ & ND & $1.1 \pm 1.6$ & ND \\
\hline
\end{tabular}

ND, not determined.

${ }^{a}$ Total activity in cytosol was calculated based on the cytosolic yield recovered experimentally. The asterisks denote statistical significance when compared with activity within the same tissue of controls: $* * * P<0.001$ 

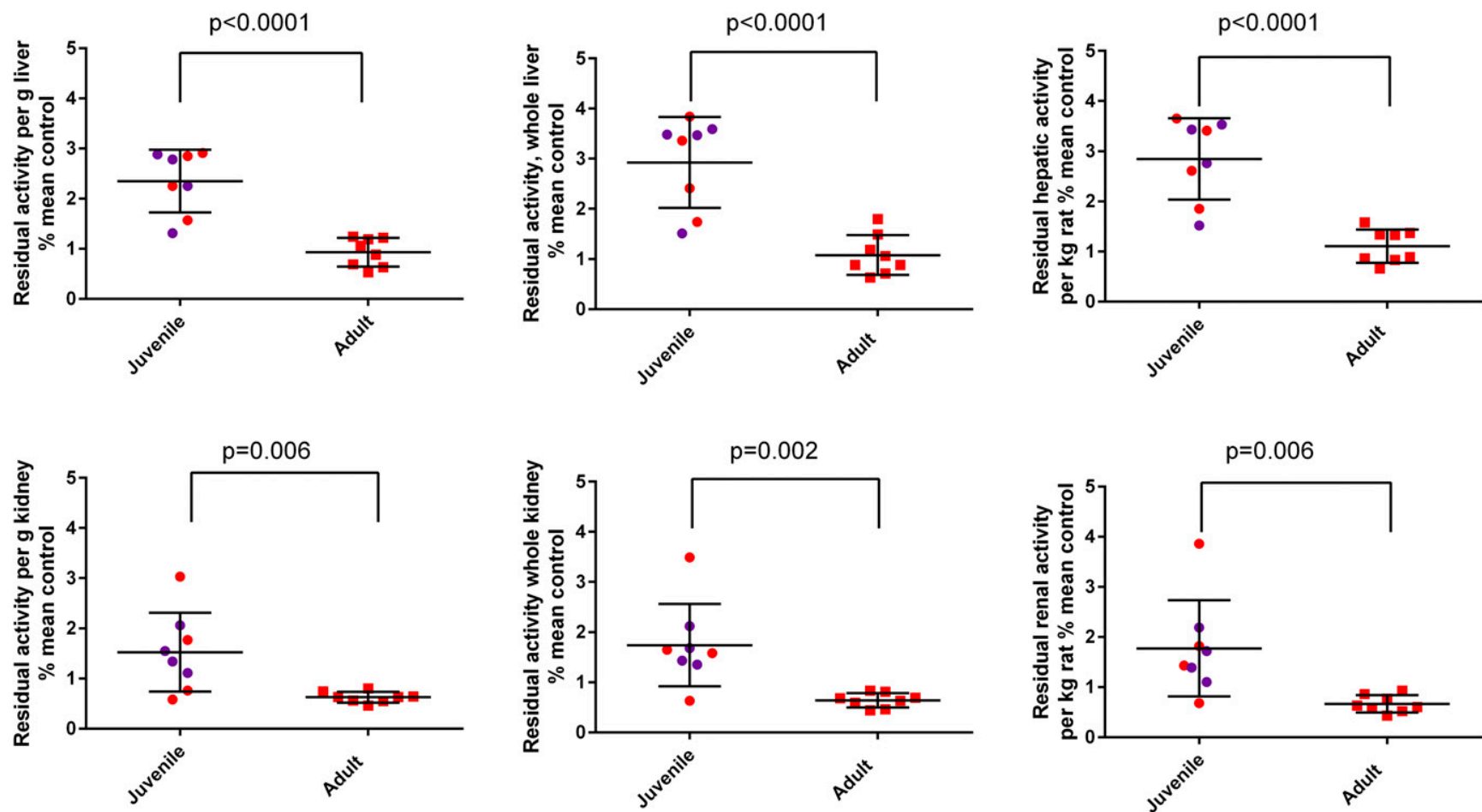

Fig. 3. Cytosolic GSTZ1 activity with DCA remaining in juvenile and adult liver (top panels) and kidney (bottom panels) of individual DCA-treated rats, expressed as percent mean control values. Values from females are shown in red and from males in purple. Data are presented per gram tissue (left panels), per whole liver or kidney (middle panels), and per kg rat (right panels). Adult activities were significantly lower than juvenile values, as indicated by the $P$ values. The data shown in the right panels are also presented in Tables 1 and 2 .

that is absent in both human and rat GSTZ1. Therefore, inclusion of the VSKDLRE motif in marmoset GSTZ1 may allow for the productive binding and catalytic turnover of EPNPP. This might explain the observed discrepancy in GSTZ1 activity with EPNPP between species.

The DCA concentrations in tissues from younger rats were much lower than those in adults (Table 3), reflective of the higher total ability of young rats to metabolize DCA after multiple doses. Significant changes were not observed when comparing concentrations between tissues from the same rodent group. This was a surprising observation, given the higher metabolism of DCA in liver matrices demonstrated in the current work. One explanation for this observation is the absorption, distribution, and elimination properties of DCA, which readily crosses membranes and is both water and lipid soluble. Studies in male Sprague Dawley rats show radioactivity from $\left[{ }^{14} \mathrm{C}\right]$ is widely distributed in liver, kidney, heart, brain, spleen, lung, and muscle after dosing with $\left[{ }^{14} \mathrm{C}\right]$-DCA (James et al., 1998). Female Sprague Dawley rats given a single oral dose of DCA, $100 \mathrm{mg} / \mathrm{kg}$, and sacrificed at different times after the dose did not show any age-related differences in absorption, as similar concentrations were found in liver at 15 minutes after the dose in juvenile and adult rats (Smeltz et al., 2019). Since repetitive DCA dosing results in the autoinhibition of DCA metabolism, the unchanged DCA can be absorbed and evenly distributed to tissues. This is reflected in the current work by the presence of DCA in brain, heart, kidney, and liver organs 24 hours after the last dose.

In summary, this was the first study to examine the contribution of extrahepatic tissues to DCA metabolism after repetitive dosages of a therapeutic concentration of DCA. Repetitive DCA dosing markedly reduced GSTZ1 in liver, kidney, heart, and brain, although the greatest expression and activity levels were retained in the liver. In general, the influence of repetitive DCA dosing on the contributions of liver and extrahepatic tissues to the GSTZ1-catalyzed metabolism of DCA was not affected by age or gender, although the retention of total GSTZ1 activity in liver and kidney cytosol was higher in 4-week-old rats than 52-week-old rats. Lastly, the lower DCA concentrations in tissues of

TABLE 3

DCA concentrations (microgram DCA per gram tissue) in 4- and 52-week-old rats given eight daily oral doses of $100 \mathrm{mg} / \mathrm{kg}$ sodium DCA

Values are means \pm S.D.. DCA concentrations in liver, kidney and brain were significantly different between age groups by ANOVA, P = 0.011 (liver), 0.0095 (kidney), and 0.005 (brain). Multiple comparisons showed concentrations in young rats were significantly lower than adults $* \mathrm{P}<0.05$.

\begin{tabular}{|c|c|c|c|}
\hline Tissue & 52-wk female $(n=8)$ & 4-wk female $(n=4)$ & 4-wk male $(n=4)$ \\
\hline & microgram DCA per gram tissue & microgram DCA per gram tissue & microgram DCA per gram tissue \\
\hline Liver & $47.11 \pm 27.13$ & $10.06 \pm 6.59^{*}$ & $11.11 \pm 4.28^{*}$ \\
\hline Kidney & $34.97 \pm 13.77$ & $16.42 \pm 9.85^{*}$ & $11.94 \pm 4.90^{*}$ \\
\hline Brain & $20.44 \pm 7.27$ & $8.32 \pm 5.03^{*}$ & $8.47 \pm 2.26^{*}$ \\
\hline Heart & $48.49 \pm 20.03$ & ND & ND \\
\hline
\end{tabular}

ND, not determined. 
juvenile rats were a reflection of the larger liver size and higher clearance of DCA observed in younger populations.

\section{Acknowledgments}

We thank Katherine Cisneros for her assistance in rodent tissue collection and preparation of subcellular fractions. We also thank Stephen C. Jahn for his assistance with the Western blotting protocol.

\section{Authorship Contributions}

Participated in research design: Squirewell, Smeltz, Rowland-Faux, Stacpoole, James.

Conducted experiments: Squirewell, Smeltz, Rowland-Faux, Horne, James. Performed data analysis: Squirewell, Rowland-Faux, Horne, James.

Wrote or contributed to writing of the manuscript: Squirewell, Smeltz, Rowland-Faux, Horne, Stacpoole, James.

\section{References}

Abdelmalak M, Lew A, Ramezani R, Shroads AL, Coats BS, Langaee T, Shankar MN, Neiberge RE, Subramony SH, and Stacpoole PW (2013) Long-term safety of dichloroacetate in congenital lactic acidosis. Mol Genet Metab 109:139-143.

Anderson WB, Board PG, Gargano B, and Anders MW (1999) Inactivation of glutathione transferase zeta by dichloroacetic acid and other fluorine-lacking alpha-haloalkanoic acids. Chem Res Toxicol 12:1144-1149.

Blackburn AC, Woollatt E, Sutherland GR, and Board PG (1998) Characterization and chromosome location of the gene GSTZ1 encoding the human Zeta class glutathione transferase and maleylacetoacetate isomerase. Cytogenet Cell Genet 83:109-114.

Board PG and Anders MW (2011) Glutathione transferase zeta: discovery, polymorphic variants, catalysis, inactivation, and properties of Gstz1-/- mice. Drug Metab Rev 43:215-225.

Board PG, Baker RT, Chelvanayagam G, and Jermiin LS (1997) Zeta, a novel class of glutathione transferases in a range of species from plants to humans. Biochem J 328:929-935.

Board PG, Chelvanayagam G, Jermiin LS, Tetlow N, Tzeng HF, Anders MW, and Blackburn AC (2001) Identification of novel glutathione transferases and polymorphic variants by expressed sequence tag database analysis. Drug Metab Dispos 29:544-547.

Boxenbaum H (1980) Interspecies variation in liver weight, hepatic blood flow, and antipyrine intrinsic clearance: extrapolation of data to benzodiazepines and phenytoin. $J$ Pharmacokinet Biopharm 8:165-176.

Calcutt NA, Lopez VL, Bautista AD, Mizisin LM, Torres BR, Shroads AL, Mizisin AP, and Stacpoole PW (2009) Peripheral neuropathy in rats exposed to dichloroacetate. J Neuropathol Exp Neurol 68:985-993.

Cornett R, James MO, Henderson GN, Cheung J, Shroads AL, and Stacpoole PW (1999) Inhibition of glutathione S-transferase zeta and tyrosine metabolism by dichloroacetate: a potential unifying mechanism for its altered biotransformation and toxicity. Biochem Biophys Res Commun 262 752-756.

DeAngelo AB, Daniel FB, Most BM, and Olson GR (1996) The carcinogenicity of dichloroacetic acid in the male Fischer 344 rat. Toxicology 114:207-221.

DeAngelo AB, Daniel FB, Stober JA, and Olson GR (1991) The carcinogenicity of dichloroacetic

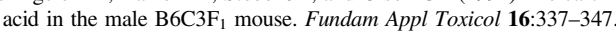

Fleischer S, Oliver McIntyre J, and Vidal JC (1979) Large-scale preparation of rat liver mitochondria in high yield, Biomembranes Part F: Bioenergetics: Oxidative Phosphorylation pp 32-39, Elsevier, Amsterdam, Netherlands.

Gonzalez-Leon A, Schultz IR, Xu G, and Bull RJ (1997) Pharmacokinetics and metabolism of dichloroacetate in the F344 rat after prior administration in drinking water. Toxicol Appl Pharmacol 146:189-195.

Habig WH, Pabst MJ, and Jakoby WB (1974) Glutathione S-transferases. The first enzymatic step in mercapturic acid formation. $J$ Biol Chem 249:7130-7139.

IARC Working Group on the Evaluation of Carcinogenic Risks to Humans (2014) Trichloroethylene, tetrachloroethylene, and some other chlorinated agents. IARC Monogr Eval Carcinog Risks Hum 106:1-512.

Jahn SC, Smeltz MG, Hu Z, Rowland-Faux L, Zhong G, Lorenzo RJ, Cisneros KV, Stacpoole PW, and James MO (2018) Regulation of dichloroacetate biotransformation in rat liver and extrahepatic tissues by GSTZ1 expression and chloride concentration. Biochem Pharmacol 152: 236-243.

James MO, Jahn SC, Zhong G, Smeltz MG, Hu Z, and Stacpoole PW (2017) Therapeutic applications of dichloroacetate and the role of glutathione transferase zeta-1. Pharmacol Ther 170:166-180

James MO and Stacpoole PW (2016) Pharmacogenetic considerations with dichloroacetate dosing. Pharmacogenomics 17:743-753.

James MO, Yan Z, Cornett R, Jayanti VM, Henderson GN, Davydova N, Katovich MJ, Pollock B and Stacpoole PW (1998) Pharmacokinetics and metabolism of [14C]dichloroacetate in male Sprague-Dawley rats. Identification of glycine conjugates, including hippurate, as urinary metabolites of dichloroacetate. Drug Metab Dispos 26:1134-1143.

Jia M, Coats B, Chadha M, Frentzen B, Perez-Rodriguez J, Chadik PA, Yost RA, Henderson GN, and Stacpoole PW (2006) Human kinetics of orally and intravenously administered low-dose 1,2-(13)C-dichloroacetate. J Clin Pharmacol 46:1449-1459.

Kankotia S and Stacpoole PW (2014) Dichloroacetate and cancer: new home for an orphan drug? Biochim Biophys Acta 1846:617-629.
Kaufmann P, Engelstad K, Wei Y, Jhung S, Sano MC, Shungu DC, Millar WS, Hong X, Gooch CL, Mao X, et al. (2006) Dichloroacetate causes toxic neuropathy in MELAS: a randomized, controlled clinical trial. Neurology 66:324-330.

Lantum HBM, Baggs RB, Krenitsky DM, Board PG, and Anders MW (2002a) Immunohistochemical localization and activity of glutathione transferase zeta (GSTZ1-1) in rat tissues. Drug Metab Dispos 30:616-625.

Lantum HBM, Liebler DC, Board PG, and Anders MW (2002b) Alkylation and inactivation of human glutathione transferase zeta (hGSTZ1-1) by maleylacetone and fumarylacetone. Chem Res Toxicol 15:707-716

Li T, Schultz I, Keys DA, Campbell JL, and Fisher JW (2008) Quantitative evaluation of dichloroacetic acid kinetics in human--a physiologically based pharmacokinetic modeling investigation. Toxicology 245:35-48.

Li W, Gu Y, James MO, Hines RN, Simpson P, Langaee T, and Stacpoole PW (2012) Prenatal and postnatal expression of glutathione transferase $\zeta 1$ in human liver and the roles of haplotype and subject age in determining activity with dichloroacetate. Drug Metab Dispos 40:232-239.

Li W, James MO, McKenzie SC, Calcutt NA, Liu C, and Stacpoole PW (2011) Mitochondrion as a novel site of dichloroacetate biotransformation by glutathione transferase zeta 1. J Pharmacol Exp Ther 336:87-94.

Mangal N, James MO, Stacpoole PW, and Schmidt S (2018) Model informed dose optimization of dichloroacetate for the treatment of congenital lactic acidosis in children. J Clin Pharmacol 58: 212-220.

Miller JW and Uden PC (1983) Characterization of nonvolatile aqueous chlorination products of humic substances. Environ Sci Technol 17:150-157.

Noda T, Todani T, Watanabe Y, and Yamamoto S (1997) Liver volume in children measured by computed tomography. Pediatr Radiol 27:250-252.

Quinn R (2005) Comparing rat's to human's age: how old is my rat in people years? Nutrition 21: $775-777$.

Saghir SA and Schultz IR (2005) Toxicokinetics and oral bioavailability of halogenated acetic acids mixtures in naïve and GSTzeta-depleted rats. Toxicol Sci 84:214-224.

Schultz IR and Sylvester SR (2001) Stereospecific toxicokinetics of bromochloro- and chlorofluoroacetate: effect of GST-zeta depletion. Toxicol Appl Pharmacol 175:104-113.

Shangraw RE and Fisher DM (1996) Pharmacokinetics of dichloroacetate in patients undergoing liver transplantation. Anesthesiology 84:851-858.

Shroads AL, Guo X, Dixit V, Liu H-P, James MO, and Stacpoole PW (2008) Age-dependent kinetics and metabolism of dichloroacetate: possible relevance to toxicity. J Pharmacol Exp Ther 324:1163-1171.

Shroads AL, Langaee T, Coats BS, Kurtz TL, Bullock JR, Weithorn D, Gong Y, Wagner DA, Ostrov DA, Johnson JA, et al. (2012) Human polymorphisms in the glutathione transferase zeta $1 /$ maleylacetoacetate isomerase gene influence the toxicokinetics of dichloroacetate. $J$ Clin Pharmacol 52:837-849.

Smeltz MG, Hu Z, Zhong G, Jahn SC, Rowland-Faux L, Horne LP, Stacpoole PW, and James MO (2019) Mitochondrial glutathione transferase zeta 1 is inactivated more rapidly by dichloroacetate than the cytosolic enzyme in adult and juvenile rat liver. Chem Res Toxicol 32: 2042-2052.

Stacpoole PW (2011) The dichloroacetate dilemma: environmental hazard versus therapeutic goldmine--both or neither? Environ Health Perspect 119:155-158.

Stacpoole PW, Henderson GN, Yan Z, and James MO (1998) Clinical pharmacology and toxicology of dichloroacetate. Environ Health Perspect 106 (Suppl 4):989-994.

Stacpoole PW, Martyniuk CJ, James MO, and Calcutt NA (2019) Dichloroacetate-induced peripheral neuropathy. Int Rev Neurobiol 145:211-238.

Stacpoole PW, Shuster J, Thompson JLPS, Prather RA, Lawson LA, Zou B, Buchsbaum R, and Nixon SJ (2018) Development of a novel observer reported outcome tool as the primary efficacy outcome measure for a rare disease randomized controlled trial. Mitochondrion $\mathbf{4 2}$ 59-63.

Tian DD, Bennett SK, Coupland LA, Forwood K, Lwin Y, Pooryousef N, Tea I, Truong TT, Neeman T, Crispin P, et al. (2019) GSTZl genotypes correlate with dichloroacetate pharmacokinetics and chronic side effects in multiple myeloma patients in a pilot phase 2 clinical trial. Pharmacol Res Perspect 7:e00526.

Tong Z, Board PG, and Anders MW (1998) Glutathione transferase zeta-catalyzed biotransformation of dichloroacetic acid and other alpha-haloacids. Chem Res Toxicol 11: 1332-1338.

Tzeng HF, Blackburn AC, Board PG, and Anders MW (2000) Polymorphism- and speciesdependent inactivation of glutathione transferase zeta by dichloroacetate. Chem Res Toxicol 13: 231-236.

Uno Y, Murayama N, Kunori M, and Yamazaki H (2013) Systematic identification and characterization of glutathione S-transferases in cynomolgus macaque. Biochem Pharmacol 86: 679-690.

Uno Y, Uehara S, Tanaka S, Murayama N, and Yamazaki H (2020) Systematic characterization of glutathione S-transferases in common marmosets. Biochem Pharmacol 174:113835.

Yan Z, Henderson GN, James MO, and Stacpoole PW (1997) Determination of dichloroacetate and its metabolites in human plasma by gas chromatography-mass spectrometry. $J$ Chromatogr $B$ Biomed Sci Appl 703:75-84

Zhong G, Li W, Gu Y, Langaee T, Stacpoole PW, and James MO (2014) Chloride and other anions inhibit dichloroacetate-induced inactivation of human liver GSTZ1 in a haplotype-dependent manner. Chem Biol Interact 215:33-39.

Address correspondence to: Dr. Margaret O. James, Department of Medicinal Chemistry, University of Florida College of Pharmacy, 1345 Center Dr., Gainesville, FL 32610. E-mail: mojames@ufl.edu 